\title{
FINAL REPORT TO DOE
}

\section{MATCHING GRANT PROGRAM}

\author{
for the
}

PENN STATE UNIVERSITY

NUCLEAR ENGINEERING PROGRAM

DE-FG02-95NE38108

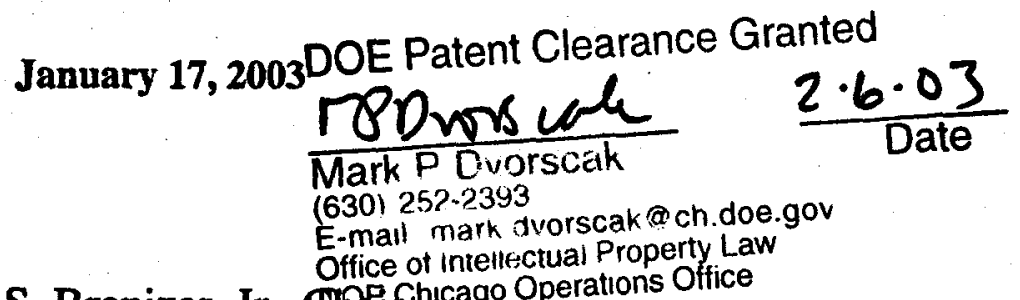

Jack S. Brenizer, Jr., ERRfifhicago Operations Office

cak ch.doe.gov

E-mail mark dvorscak

Nuclear Engineering Program

Department of Mechanical and Nuclear Engineering

\author{
U.S. DEPARTMENT OF ENERGY
}

\section{OFFICE OF NUCLEAR ENERGY, SCIENCE AND TECHNOLOGY \\ DOE/INDUSTRY MATCHING GRANT PROGRAM}




\section{DISCLAIMER}

This report was prepared as an account of work sponsored by an agency of the United States Government. Neither the United States Government nor any agency thereof, nor any of their employees, makes any warranty, express or implied, or assumes any legal liability or responsibility for the accuracy, completeness, or usefulness of any information, apparatus, product, or process disclosed, or represents that its use would not infringe privately owned rights. Reference herein to any specific commercial product, process, or service by trade name, trademark, manufacturer, or otherwise does not necessarily constitute or imply its endorsement, recommendation, or favoring by the United States Government or any ageacy thereof. The views and opinions of authors expressed herein do not necessarily state or reflect those of the United States Government or any agency thereof. 


\section{DISCLAIMER}

Portions of this document may be illegible in electronic image products. Images are produced from the best avallable original document. 


\section{INTRODUCTION}

The DOE/Industry Matching Grant Program, which began in 1992, was designed to encourage collaborative support for nuclear engineering education as well as research between the nation's nuclear industry and the U.S. Department of Energy (DOE). Through the 1980's and 90's, nuclear engineering programs in the United States witnessed a serious decline in student enrollments, number of faculty members and support from their host universities. Despite this decline, the discipline of nuclear engineering remained important to the advancement of the mission goals of the U.S. Department of Energy. These academic programs are also critically important in maintaining a viable workforce for the nation's nuclear industry. As conceived by Commonwealth Edison, this program has focused on creating a partnership between DOE and private sector businesses, which employ nuclear engineers. The program is designed to ensure that academic programs in nuclear engineering are maintained and enhanced in universities throughout the United States.

\section{BACKGROUND}

The Nuclear Engineering undergraduate curriculum has a strong emphasis in areas traditionally associated with nuclear power production. These include courses in thermal hydraulics, nuclear core design, power plant simulation, reactor instrumentation and control, fuel management, nuclear materials, nuclear reactor safety, and neutron transport theory. Additionally, students take courses in radiation detection, radiation safety, heat transfer, fluid flow, and thermodynamics, as well as mathematics and mechanics. Available experimental courses include a reactor physics laboratory, a reactor operations laboratory, a thermal hydraulic laboratory and an instrumentation and control laboratory. The Master of Science program requires 30 credits, including 12 credits of advanced courses. The Ph.D. program does not require a specific number of courses, however, the students continue their studies in a specific area for specialization. They then perform state-of-the-art research, which becomes their thesis topic. Each graduate program is individually tailored to fit the background and the needs of the student.

Penn State conducts cutting-edge research in neutronic and thermal-hydraulic modeling, reactor control, reactor simulation, radiation transport, transient safety analysis, and in the nuclear sciences. We have outstanding experimental facilities at the Radiation Science and Engineering Center, including a $1 \mathrm{MW}$ nuclear reactor, a gamma pool, and various research laboratories, e.g. a neutron radiography laboratory, a thermal hydraulic test facility and a materials research laboratory. A basic principles training simulator is also available for several simulation courses, as well as for undergraduate and graduate research projects.

The Accreditation Board for Engineering and Technology (ABET) reviewed all engineering programs at Penn State in Fall 2002 as part of the normal review every six years. Based on the reviewers' findings, we anticipate our nuclear engineering program will be re-accredited for six more years.

\section{IMPACT OF DOE/INDUSTRY MATCHING GRANT FUNDING}


The Department of Nuclear Engineering was merged with the Department of Mechanical Engineering in July 1998. The merger was in a large part the result of declining enrollments in the undergraduate nuclear engineering program, reaching the low point in 1997. The Matching Grant Program played a critical role in the survival of the Penn State Nuclear Engineering degree programs, providing funding for infrastructure and student support beyond that available from the University. Now, the Nuclear Engineering Program is a separate degree program in the Department of Mechanical and Nuclear Engineering, offering nuclear engineering degrees at the Bachelor's, Master's and Ph.D. level. The program's Fall 02 enrollments were: 72 B.S., 12 M.S. and 32 Ph.D. students. The B.S. enrollment numbers are for declared nuclear engineering majors only. At Penn State, students choose their major in the second semester of their sophomore year. While the M.S. and Ph.D. enrollments have decreased slightly, they are about on par with the moving five-year average. The B.S. enrollment rose by approximately $38 \%$ from last year. There is evidence from discussions with students and from our freshman nuclear engineering seminar course that interest in our undergraduate program is increasing. We continue to see strong administrative support at all levels of the University. The Nuclear Engineering Program at Penn State is in excellent condition and is growing.

At Penn State, the Industry/DOE Matching Grant funds were used in a variety of ways to support both undergraduate and graduate students directly. Some of these included providing seed funding for new graduate research initiatives, funding the development of new course materials, supporting new teaching facilities, maintenance and purchase of teaching laboratory equipment, and providing undergraduate scholarships, graduate fellowships and wage payroll positions for students. Through the grant period, funding to students (including hourly wage payroll, graduate assistantships, undergraduate scholarships, graduate fellowships, tuition, and fringe benefits) averaged $87 \%$ of the total Matching Grant funding. Not only has the Grant been critical to the Nuclear Engineering Program, it has provided support to many students while they worked to obtain their nuclear engineering degree.

Some specific examples of the efforts supported by Grant funding include:

- Provide scholarships to meritorious undergraduate nuclear engineering students. With Exelon and our department scholarship funding we have been able to provide scholarships (typically $\$ 1,000$ to $\$ 2,000$ per year) to all nuclear engineering students with a GPA greater than 3.0 (on a 4.0 scale).

- In the NucE 450 course, Radiation Detection and Measurement, additional equipment setups were needed due to increasing enrollments. This course is taken by all juniors and by graduate students who do not have a nuclear engineering background. New NIM counting equipment, computers and detectors were acquired for five counting stations. Additionally, new software and control boards have been purchased. The computers are used for experiment control, for data acquisition, and for plotting and information preparation for laboratory reports. Last year we added several new experiments to replace those that are now outdated and to enhance the student's knowledge of current instrumentation. In future years we anticipate adding new experimental stations

- Our surveys have shown that a significant fraction of our students come to nuclear engineering because of the positive influence of a high school physics or chemistry course 
that covered nuclear concepts. Funding was provided to support the Nuclear Science and Technology course for secondary teachers. We have a great group of teachers each summer. The course was very successful in introducing them to nuclear concepts and to national energy considerations. The faculty and staff contributed their efforts without charge. Representatives from industry made presentations on reactor operations, medical applications, waste disposal, risk assessment and analysis, and the group visited the Penn State Breazeale Reactor. Basic counting experiments were utilized to introduce the students to radiation detection and radiation interaction with matter.

- The Penn State American Nuclear Society Student Branch has been active in outreach. They have organized several events, and run a BSA Atomic Energy Merit Badge course most years. The Penn State Branch hosted the April 2002 ANS Student Conference which drew about 300 participants to Penn State. We have allocated some funding to support an outreach effort of the Penn State Student ANS, for example to give talks and demonstrations at local schools, participate in scouting badges, etc.

- A TMI-1 basic principles simulator has undergone numerous computer and software upgrades. Currently, two graduate students and several undergraduates are using the simulator for research. The simulator has been incorporated into two existing courses. A special topics course based on this simulator (NucE 497E) was being offered for the fourth time last spring.

- Research was enhanced through the support by providing a graduate research assistant to work on new research projects. We have several professors who have proposed research in new areas, but are held back by the lack of student support: Providing an assistantship enabled us to expand our research base, making our graduate program more attractive to prospective students. Over the matching grant program duration, we have had several students conduct MS thesis research related to the nuclear power industry and Exelon nuclear power plants in particular.

- The senior undergraduate Nuclear Engineering courses in reactor physics (NucE 403) and core design (NucE $431 \mathrm{~W}$ ) were improved introducing state-of-practice computer software. The same software programs are now utilized in our graduate fuel management (NucE 512) and reactor kinetics and dynamics (NucE 597K) courses. All of our undergraduates and many of our graduate students utilize these analysis programs. In addition, we updated our nuclear reactor systems course (NucE 430), a required course that has not been significantly revised for many years. A graduate assistant worked with the faculty member responsible for this course to incorporate the changes.

- Recruiting of students at both the undergraduate and graduate level continued to be a critical activity within our program throughout the duration of the grant period. Our industry colleagues played an important role in our recruiting efforts. Their presence at recruiting events, especially at the fall and spring College of Engineering Open House events, has been very helpful and well received by both prospective students and their parents. Nuclear Engineering faculty members have been working very hard to increase the program's visibility to prospective majors (Penn State sophomore engineering students). We feel our recruiting effort cannot be reduced, even with the increased undergraduate enrollment. Since 
the freshman seminar is playing a major role in raising interest in nuclear engineering, we used some Matching Grant funds to develop and add experiments and demonstrations.

\section{CONCLUSION}

The DOE Matching Grants Program provided support for nuclear engineering programs that was not readily available from other sources. This funding was and remains critical to the viability of our nuclear program. The number of students enrolled in both undergraduate and graduate programs has a major impact on the funding received from the University, both in direct funding allocations and indirect ways, such as the number of graduate teaching assistantships allocated to the major. Through the last two decades, when enrollment was declining, DOE/Industry Matching Grant funding allowed us to continue to offer nuclear engineering students a quality program. We have identified recruiting at both the undergraduate and graduate levels as an area for continued support. We want to attract academically strong students both by increasing our visibility to prospective students and by further strengthening our academic programs. The planned upgrades of our nuclear engineering courses and facilities, such as the radiation detection laboratory, the simulator and the thermal hydraulic test loop, will help us in recruiting these strong students and will enhance the academic experience of our current students. Development of a new research area will enhance our graduate recruiting.

The DOE Matching Grants Program is very valuable to the nation's nuclear engineering educational programs. In some cases it is critical to the continuation of a program. 